- improvement of herbicide application methods to give maximum effectiveness while maintaining or reducing the current low risk levels to health and the environment; and

- development of more acceptable methods and chemicals for combating forest weeds.

The herbicide research capabilities and responsibilities of the CFS's Forest Pest Management Institute and regional research establishments must be significantly improved and expanded.

Research and registration programs should be co-ordinated with their counterparts in the United States, possibly through a bilateral, co-operative agreement.

There is a need for improved and standardized monitoring of herbicide applications, and training and certification of applicators.

An adequately and jointly funded education and relations program should be mounted under a committee comprised of the federal departments of Environment, Health and Welfare, Fisheries and Oceans, and Agriculture with a standing advisory board of industrial and governmental pesticide and communications experts. Provincial (or regional) subcommittees should be established in the same fashion, comprised of representatives of involved provincial government departments, regional CFS establishments, and involved companies.

The public review process is extremely important and necessary, but must be structured in a way that the public in its broadest sense is fully involved and fully briefed on the issues, choices, benefits and risks involved in forest herbicide projects.

Mechanical and manual weeding techniques should be preferred under suitable conditions where they will be effective and provided that socio-economic impacts of these labour intensive and publicly preferred treatments are positive. The higher costs of these treatments should be considered in the context of total government budgets (welfare and unemployment) for justification purposes.

Training and research in brush management and prevention should be increased in Canada's universities and technical schools

R.J. Bourchier Executive Director

\section{Forest Policy Issues and Developments}

\section{British Columbia}

Through the 1983-1988 Five Year Forest and Range Resource Program, the Government of the Province of British Columbia has set priorities of the Ministry of Forests to include "to reduce the size of the Ministry, to increase the role of the private sector, and to aid, enhance and support the economic recovery in the forest sector to the greatest possible degree". To assist in fulfilling this mandate, the Ministry of Forests has prepared a public discussion paper entitled "Forest Management Partnership Proposal - Tree Farm Licences"

\section{W. Young \\ Chief Forester Ministry of Forests Province of British Columbia}

\section{Erratum}

The October issue of the Forestry Chronicle carried on page 217 a statement by W.T. Foster. Deputy Minister with the Ontario Ministry of Natural Resources dealing with natural resources research. The statement as printed contains an unfortunate error in that the word "not" was inadvertently inserted in the last sentence of the fourth paragraph. This completely changes the meaning and says the Ministry should not generate or fund the production of knowledge. Mr. Foster is saying that direct generation of knowledge is not the Ministry's business but fuding it is. The correct fourth paragraph follows:

"With reference to the traditional roles of government, i.e. legislation, regulation and monitoring, I do not see the generation of scientific knowledge by the Ministry as a legitimate role in the present circumstances. The funding and direction of research so that specific knowledged is available to government does however fall within the traditional role of government.'

W.B.G. Denyer

\section{New Working Groups?}

At the 75th meeting in Sault Ste Marie the possibility of forming two new working groups was discussed by the Executive and the Forest Science \& Technology Board. Suggestions have been received to form working groups in Forest Utilization and in Private Land Forestry. At present there are working groups in the following areas:

Forest Ecology

Forest Economics and Policy

Forest Education

Forest Entomology and Pathology

Forest Fire Control Science

Forest Harvesting

Forest Hydrology

Land Use Planning

Forest Landscape, Recreation and Tourism

Forest Management

Forest Measurement

Silviculture and Tree Improvement

Urban Forestry

Wildlife and Fish Habitat

International Forestry

The Executive is looking for an expression of opinion from the membership at large on the need for and usefulness of working groups in these two areas. You will recall that working groups are to provide a focus for members with a common interest; promote the production of articles and presentations for The Forestry Chronicle and annual meetings, and provide a pool of expertise in specific areas to conduct or help conduct special assignments to develop CIF/IFC positions, plan meetings etc.

Some working groups have been very active and others virtually inactive. The latter are being reviewed now for possible revitalization or abolition. It is important to create only groups that have a real purpose and can make a solid contribution to Institute affairs. Please send your thoughts on the wisdom of forming these Working groups to the Executive Director.

R.J. Bourchier 